\title{
EXHAUST GAS MODELING EFFECTS ON HYPERSONIC POWERED SIMULATION AT MACH 10
}

\author{
Kenneth E. Tatum* \\ Lockheed Engineering \& Sciences Co. \\ Hampton, Virginia \\ and \\ Lawrence D. Huebner ${ }^{\dagger}$ \\ NASA Langley Research Center \\ Hampton, Virginia
}

\begin{abstract}
A numerical study was performed to investigate the accuracy and vali dity of cold-gas simulation of actual hot scramjet exhaust within a Mach 10 free stream over a representative single-stageto-orbit airbreathing configuration. In particular, exhausts of various noncombusting chemistry models were studied to characterize their effects on the vehicle aftbody performance and the plume flow field definition. Two approximations of the hot scramjet combustion products were utilized to determine the requirement for expensive, multi-species numerical modeling, and to establish a baseline for the validation of cold-gas simulation. Cold-gas simulation at Mach 10 is shown to be a viable technique using an appropriate thermally perfect gas mixture for reproducing hot scramjet exhaust effects.
\end{abstract}

\section{Introduction}

Prior to the National Aero-Space Plane (NASP) program in the United States of America very little was known regarding the effects that powered scramjet exhaust flow fields would have on the aftbody of the vehicle, particularly on the aerodynamic and control surfaces. Such exhaust flow field effects are commonly referred to as jeteffects. Actual air/hydrogen scramjet propulsion is not a scalable process, and the sizing of a flowthrough, fuel-injection, combustion engine system in a typically small hypersonic wind tunnel model is extremely difficult. Therefore, other approaches, known as exhaust simulation, were

\footnotetext{
* Staff Engineer, Senior Member AIAA

$\dagger$ Aerospace Engineer, Hypersonic Airbreathing Propulsion Branch, Gas Dynamics Division, Senior Member AIAA
}

assessed. Through the course of the NASP program many exhaust simulation techniques were studied for obtaining data describing these jeteffects using wind tunnel models that produce a simulated scramjet exhaust.

One such approach proposed using a miniature combustor fed by two separate gas lines, one for hydrogen and one for oxygen. The resulting combustion products approached appropriate scramjet exhaust temperatures, but lacked the significant amount of nitrogen species found in air/hydrogen combustion. Furthermore, this technique is very expensive in terms of model design and fabrication, as well as in the potential expense of modifying a facility for safe operation with this type of combustion.

Alternatively, Oman, et al., ${ }^{\mathbf{1}}$ developed a method to use a non-combusting, thermally perfect gas at 'cold' temperatures to simulate the gas dynamic effects caused by air/hydrogen combustion products in a hot exhaust external nozzle flow field. Herein 'cold' refers to temperatures much less than those occurring in air/hydrogen combustion. This simulant (cold) gas concept is based upon matching the ratio of specific heats $\gamma$ of the exhaust gas, the Mach number, and the static pressure ratio throughout the exhaust flow field. Oman, et al., used a mixture of Freon-12 and argon (Ar), two inert gases, to provide a $\gamma$ close to that obtained from actual combustion, where $\gamma$ is a function of temperature. Aftbody surface pressures obtained using the Freon/Ar mixture compared well with combustion data obtained on the same model ${ }^{2}$. Because of the reduction in facility operations safety concerns and model complexity, compared to the air/hydrogen combustion method, this method was adopted by NASA Langley for work on studies

This paper is declared a work of the U.S. Government and is not subject to copyright protection in the United States 
related to the NASP ${ }^{3}$. (Tetrafluoromethane, $\mathrm{CF}_{4}$, has since been substituted for the chlorofluorocarbon Freon-12 which has been found to be destructive to the ozone layer. $\mathrm{CF}_{4}$ has properties similar to F reon-12, but without the harmful chlorine component.)

At the NASA Langley Research Center, the Test Technique Demonstrator (TTD) model was conceived to investigate a wide variety of wind tunnel testing techniques associated with airbreathing, single-stage-to-orbit (SSTO) vehicles. As a complementary effort, computational fluid dynamics (CFD) solutions of this configuration were performed for CFD code calibration/validation and to better understand the flow physics associated with this class of vehicle. A large part of this experimental and computational research was focussed on understanding the effects of scramjet exhaust aftbody flow fields. Computationally, these included powered effects due to angle of attack ${ }^{\mathbf{4}}$, and effects of inlet representation on aftbody flows ${ }^{\mathbf{5}}$. In the current study, differences in aftbody performance and plume flow field definition resulting from various degrees of complexity of exhaust gas modeling were examined computationally through the use of four exhaust chemistry models. Previous studies at Mach $6^{\mathbf{6 , 7}}$ concluded that cold-gas simulation of scramjet exhaust flows is a viable approximation to actual hot scramjet exhaust at that Mach number. The cold, reduced- $\gamma$ exhaust of a $\mathrm{CF}_{4}$-Ar mixture yields slightly better simulation of the plume size and shape, and the aftbody forces and moments, due to scramjet exhaust than does a cold air exhaust at Mach 6.

However, the preceding studies did not address the question of the Mach number range for which the cold-gas simulation technique is valid. In particular, does the technique retain its accuracy relative to hot exhaust flows in the free stream Mach number range (approximately 6-15) in which scramjets are primarily intended to operate? The current paper describes a numerical study of various cold and hot exhaust simulations at Mach 10. The objectives of this study were to determine the accuracies of aftbody/ plume effects due to cold-gas simulations relative to hot (noncombusting) scramjet exhaust, including two approximations to the hot scramjet exhaust.

\section{Modeling Considerations \\ Model Geometry}

The Test Technique Demonstrator (TTD) is a generic NASP-like configuration designed primarily for investigating wind tunnel test techniques for hypersonic air-breathing vehicles. Two small scale models (approximately 1.5 and 3 feet long) have been fabricated for scramjet exhaust simulation powered testing in NASA Langley's highspeed wind tunnels ${ }^{\mathbf{8 , 9}}$. Reference 8 describes methodology for using metric model parts to obtain force and moment data under powered conditions, and reference 9 describes the acquisition of powered effects data using surface and flow field pressure measurements. The conceptual airbreathing flight vehicle configuration is shown in Figure 1. However, as noted previously, true powered airbreathing, fuel-injection, combustion testing is impractical in current smallscale high-speed wind tunnels due to both tunnel and model size constraints. Instead, the forebody inlet is closed with a fairing and exhaust simulation is performed. The fairing eliminates the problem of removing the air captured by the inlet, thereby allowing a simulant gas to be routed on board and expanded out the nozzle. Computational studies have shown that a properly designed fairing has minimal effect on the aftbody/exhaust flow field $d^{5,10}$. A lower aft view of the faired-over configuration modeled in the current study is shown in Figure 2, allowing the twomodule internal nozzle to be seen. Figure 3 shows how a simulant exhaust gas is routed on board the actual wind tunnel model through the model support strut into a plenum chamber and exhausted out an internal nozzle designed to yield specified flow conditions at the exit, as described below. The support strut and external gas supply system were not model ed in this work. The internal nozzle is contained within the engine module as part of the forebody, and the

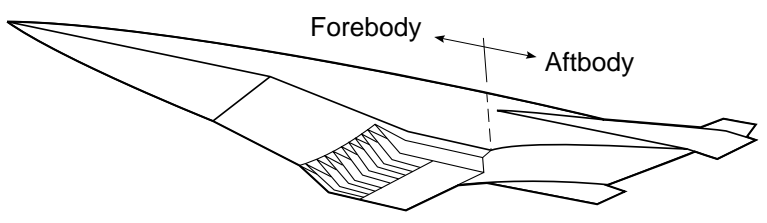

Figure 1. Test Technique Demonstrator 


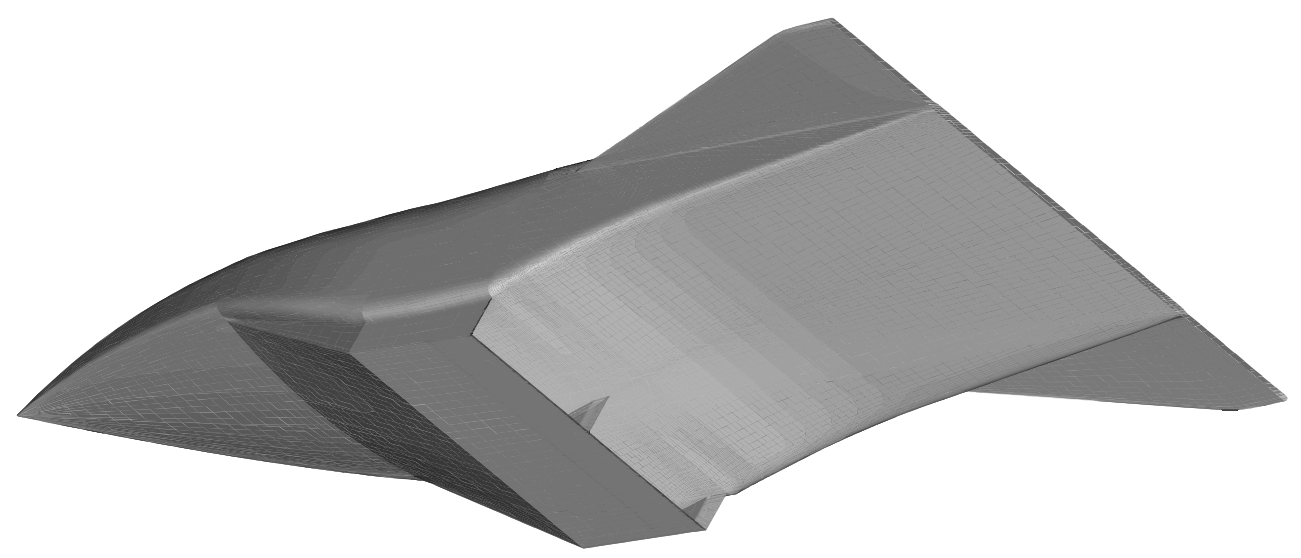

Figure 2. Full-span shaded numerical model of the TTD with wings and inlet fairing

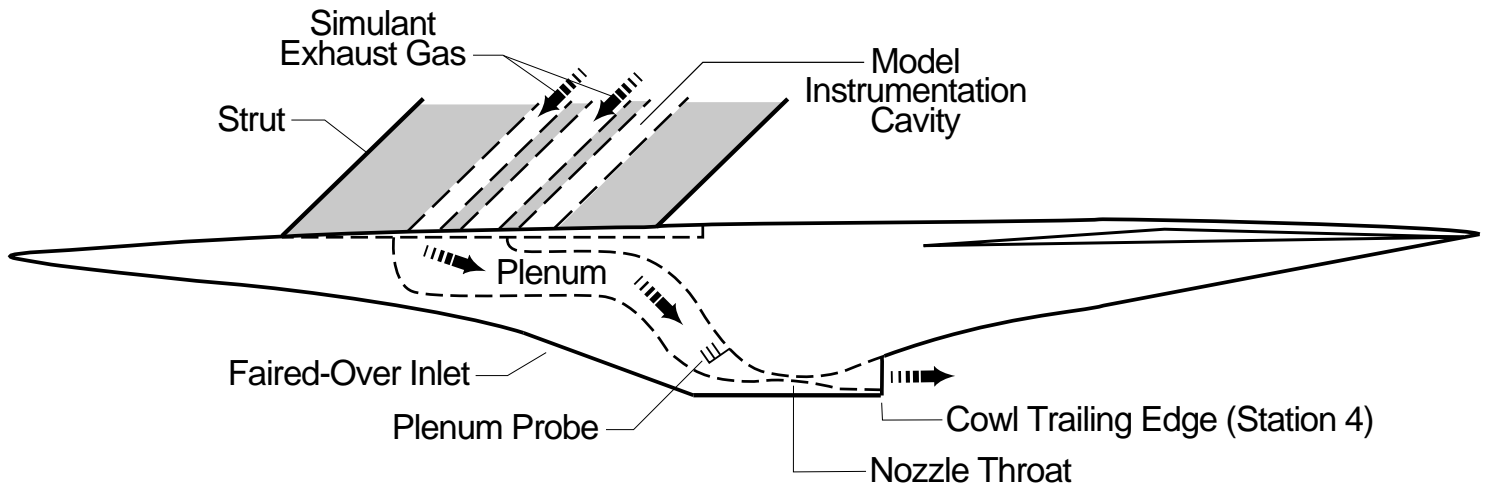

Figure 3. Schematic of small-scale model exhaust simulation flowpath

nozzle exit plane (engine cowl trailing edge) defines the downstream end of the forebody. The nozzle exit plane is designated station 4 , consistent with previous report terminology. The aftbody is the remainder of the vehicle, i.e., everything aft of the cowl trailing edge (nozzle exit plane) and includes the wings, mounted at a nominal incidence of $-1.5^{\circ}$ (leading edge down) for this study.

The simulated scramjet exhaust in this numerical study was computed beginning with a uniform Mach number of 1.03 just downstream of the nozzle throat and expanded to the cowl trailing edge (see Figure 3). Due to the variety of exhaust gas chemistry models employed in this study, each having different flow expansion characteristics, four different internal nozzles were required to provide average cowl exit-plane Mach numbers of approximately 3.4 for the appropriate exhaust gas. The nozzles for hot exhaust gases were designed to also yield average exit-plane static temperatures of approximately $3410^{\circ} \mathrm{R}$ (1895 K), typical of actual scramjet exit temperatures. The exit plane geometry was held fixed and the nozzle length was allowed to vary only 0.2 inches. The nozzle walls had sharp trailing edges to avoid recirculation regions aft of the cowl, thus allowing supersonic space-marching CFD solutions. An internal sharp-edged splitter plate at the vehicle symmetry plane divided the nozzle into two modules. Figure 4 shows a threeview schematic of a typical internal nozzle module.

\section{Flow Conditions}

The purpose of this study was to analyze the validity of cold-gas powered simulation at a typical flight Mach number in which a scramjet 


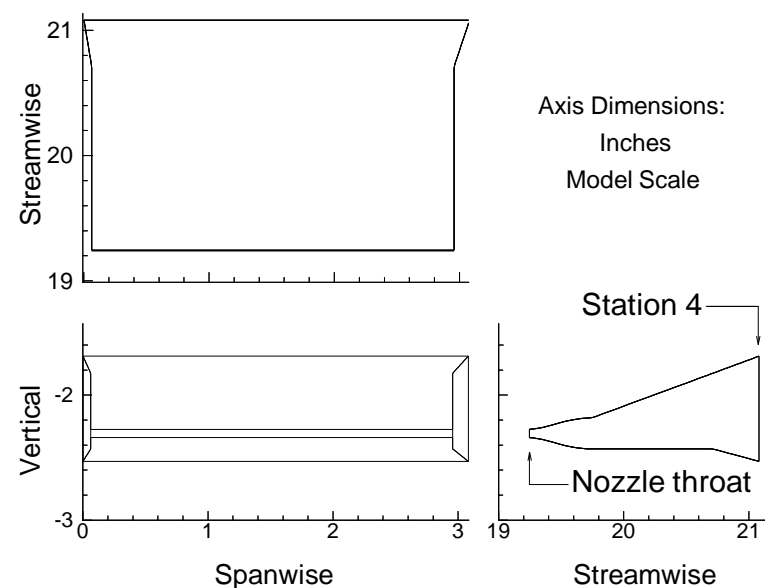

Figure 4. Internal nozzle schematic

engine would be operating. A baseline nozzle pressure ratio (NPR $=p_{t, j} / p_{\infty}$ ) of 3000 was selected as representative of Mach 10 flight, where the 't,j' refers to total (plenum) conditions of the exhaust jet. The free stream conditions were selected to match nominal conditions in the NASA LaRC 31-Inch Mach 10 Wind Tunnel: $\mathrm{Re}_{\infty}=2 \times 10^{6} / \mathrm{ft}, \mathrm{M}_{\infty}=10.14, \mathrm{p}_{\mathrm{t}, \infty}=1450 \mathrm{psi}$, and $T_{t, \infty}=1836^{\circ} \mathrm{R}$. In all cases, the external gas was thermally perfect air, model ed as a single species. A single forebody CFD solution based upon these free stream conditions was computed and combined with various internal nozzle solutions to initial ize the aftbody flow field for each solution.

Twelve internal nozzle/exhaust combinations were computed using four noncombusting, thermally perfect gas mixtures at both cold and hot (combustion) temperatures (see Table 1). Four cases used air as the exhaust gas, three at cold conditions for a range of NPR values and one hot case at the baseline NPR. Three cases used a 70/ $30 \%$ mole fraction mixture of $\mathrm{CF}_{4}$ and $\mathrm{Ar}$ at cold temperatures, the current standard simulant gas in use at NASA LaRC. These exhaust calculations were compared with two approximations to the actual composition of Mach 10 scramjet combustion products at hot temperatures. A six-species approximation, consisting of about $30 \% \mathrm{H}_{2} \mathrm{O}$ (steam), $63 \% \mathrm{~N}_{2}, 1 \% \mathrm{O}_{2}, 1 \% \mathrm{NO}, 1 \% \mathrm{Ar}$, and $4 \%$ $\mathrm{H}_{2}$, by mole fraction, accounts for all but residual species from the actual combustion process. A two-species model of approximately $32 \% \mathrm{H}_{2} \mathrm{O}$ and $68 \% \mathrm{~N}_{2}$ by mole fraction preserves the relative concentrations of the two dominant combus-
Table 1: CFD Case Summary

\begin{tabular}{|l|r|r|}
\hline Exhaust gas & $\mathrm{NPR}$ & $\mathrm{T}_{\mathrm{t}, \mathrm{j}}\left({ }^{\circ} \mathrm{R}\right)$ \\
\hline \hline Air & 2050 & 790 \\
\hline Air & 2700 & 790 \\
\hline Air & 3000 & 790 \\
\hline Air & 3000 & 9360 \\
\hline $\mathrm{CF}_{4}-\mathrm{Ar}$ & 3000 & 790 \\
\hline $\mathrm{CF}_{4}-\mathrm{Ar}$ & 3300 & 790 \\
\hline $\mathrm{CF}_{4}-\mathrm{Ar}$ & 3600 & 790 \\
\hline $\mathrm{H}_{2} \mathrm{O}-\mathrm{N}_{2}$ & 2700 & 8460 \\
\hline $\mathrm{H}_{2} \mathrm{O}-\mathrm{N}_{2}$ & 3000 & 8460 \\
\hline $\mathrm{H}_{2} \mathrm{O}-\mathrm{N}_{2}$ & 3300 & 8460 \\
\hline $\mathrm{H}_{2} \mathrm{O}-\mathrm{N}_{2}-\mathrm{O}_{2}-\mathrm{H}_{2}-\mathrm{NO}-\mathrm{Ar}^{\mathrm{a}}$ & 3000 & 8460 \\
\hline $\mathrm{H}_{2} \mathrm{O}-\mathrm{N}_{2}-\mathrm{O}_{2}-\mathrm{H}_{2}-\mathrm{NO}-\mathrm{Ar}^{\mathrm{a}}$ & 3300 & 8460 \\
\hline \hline
\end{tabular}

a. same nozzle as $\mathrm{H}_{2} \mathrm{O}-\mathrm{N}_{2}$.

tion product species at a lower computational cost. Five calculations were performed with these approximations to determine NPR effects for the hot exhaust and to determine the requirements for precisely modeling the mixture of combustion products. The same nozzle geometry and jet total temperature was used for all of the hot combustion products exhaust calculations.

While the NPR is an appropriate figure of merit for scramjet engine designers, the important simulation parameters $\mathbf{s}^{\mathbf{1}}$ are the local conditions at the nozzle exit. For more appropriate comparisons of the resulting data, a static nozzle pressure ratio $\left(S_{N P R_{4}}=p_{4} / p_{\infty}\right)$ was determined from the computed flow fields, where $p_{4}$ was evaluated just upstream of the cowl exit plane on the body-side surface of the internal nozzle (the location of pressure taps in the actual wind tunnel models).

All hot calculations were made under the assumption of thermally perfect, frozen flow, i.e., no combustion or dissociation. This assumption was reasonable downstream of the nozzle/cowl exit plane where scramjet combustion is typically considered to be complete and the static temperatures were below $3500^{\circ} \mathrm{R}$, even though it was obviously not valid at the extremely high internal 
nozzle temperatures. Since the external flow fields were the emphasis of this study, the (fictitious) internal flows were computed only to provide reasonable initial exhaust flow fields to the aftbody. The six and two-species combustion products compositions were assumed to be those at the exit plane, as provided by the frozen internal flows.

Each of the internal nozzle solutions was merged with the single forebody solution via bilinear interpolation at the cowl exit plane to initialize each aftbody flow field solution. The cases comprising the study (Table 1) were characterized by the exhaust gas mixture, jet conditions, and a corresponding internal nozzle geometry. Figure 5 shows the relationships between the NPR and $\mathrm{SNPR}_{4}$ for each case. (Note that the NPR values for the hot cases are valid only for computational purposes under the assumption of frozen flow. Experimental NPR values would be different due to the chemical reactions and dissociation occurring within the internal nozzle.) The two hot combustion products exhausts agree to within $0.6 \%$. At the baseline NPR of 3000 , the cold air exhaust is $43 \%$ higher in $\mathrm{SNPR}_{4}$ compared to the most complete (six-species) combustion products model, while the cold $\mathrm{CF}_{4}-\mathrm{Ar}$ exhaust is $4.7 \%$ lower. The slopes of the SNPR 4 versus NPR for the two hot combustion products exhausts agree within about $1.5 \%$. The cold air exhaust slope is $41 \%$ high, while the $\mathrm{CF}_{4}$ - $\mathrm{Ar}$ simulant slope is $8 \%$ low.
This wide range of data slopes complicates the task of choosing simulant NPR values to achieve appropriate station 4 conditions, especially for cold air. Using hot air does reduce the magnitude of the difference in $\mathrm{SNPR}_{4}$ considerably, but this is no more viable as a test technique than is using hot combustion products. The hot air exhaust data is presented only to illustrate temperature effects while holding the gas fixed.

\section{CFD Code Description}

The General Aerodynamic Simulation Program (GASP), version $2.0^{\text {II }}$, was the CFD code applied in the current study. GASP solves the integral form of the governing equations, including the full Reynolds-averaged Navier-Stokes equations, the Thin-Layer Navier-Stokes (TLNS) equations, the Parabolized Navier-Stokes (PNS) equations, and the Euler equations. A generalized chemistry model and both equilibrium and non-equilibrium thermodynamics models are included. The discretized equations may be solved by space marching or global iteration, and both explicit multi-stage Runge-Kutta and implicit time integration schemes are included. Characteristic-based spatial discretizations employ a variety of flux and J acobian evaluation schemes.

The code allows highly flexible coupling of multiple grid zones, each of which may be solved independently or in a coupled manner, with species differences permitted between zones, as well

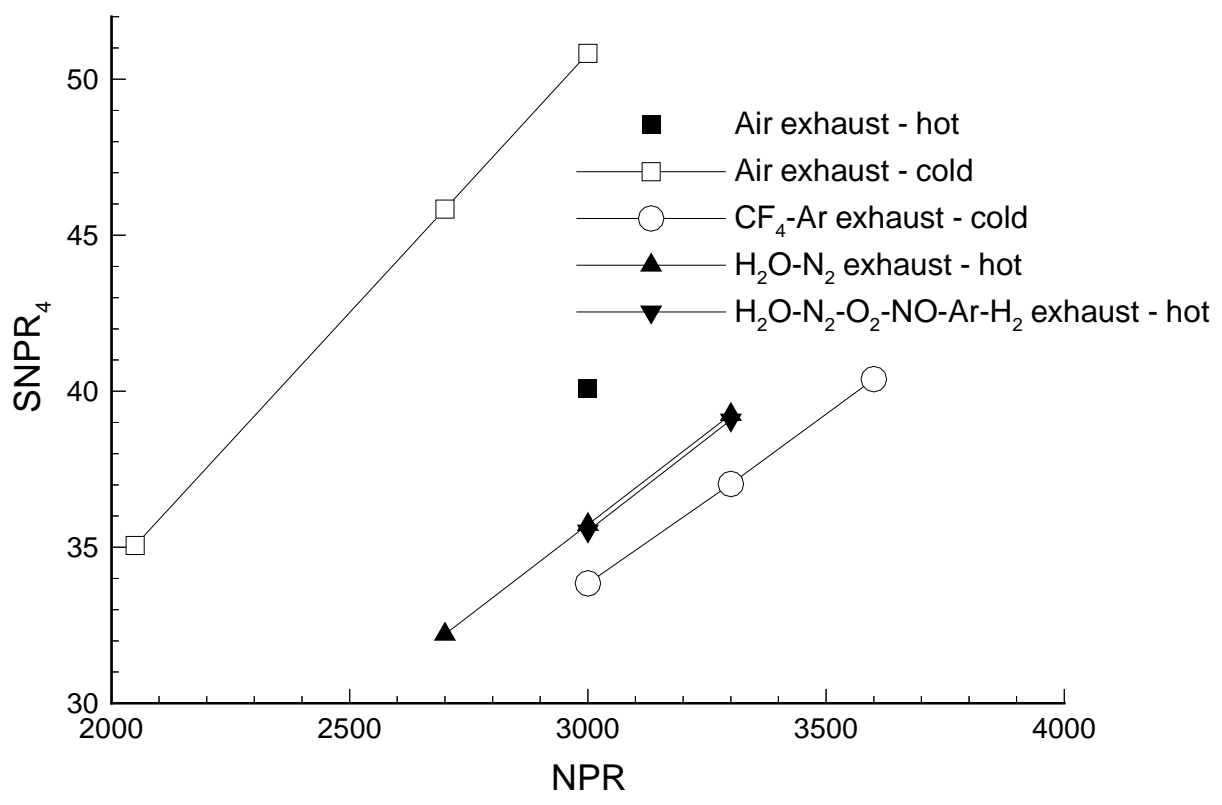

Figure 5. Variation of static nozzle pressure ratio with total nozzle pressure ratio 
as choices of numerical algorithms. All thermodynamic and transport property data for individual species are permanent parts of the code, selected at run time through input options. The solution algorithms, flux models, limiters, viscous models, boundary conditions, and initial flow conditions are all set for each zone within the input files. Grid generation for GASP is simplified due to the zonal algorithm, but grid points of adjacent zones must coincide al ong grid interface boundaries for global, or single-run, computations.

Before any CFD code can be used as an analysis tool, code calibration is essential for the types of flows of interest to provide a level of confidence in the ability of the code to accurately predict the fluid dynamics of the flow fields. Previous studies using GASP have shown that it has the ability to accurately predict complex, three-dimensional hypersonic flows including a representative NASP forebody ${ }^{\mathbf{1 2}}$, the effects of plume-induced separation ${ }^{\mathbf{1 3}}$, and three-dimensional powered effects on a model aftbody ${ }^{5}$.

\section{Numerical I ssues}

All CFD calculations in this study solved the PNS equations using third-order upwind-biased inviscid split fluxes. Laminar flow was assumed based upon the small model scale and the relatively low free stream Reynolds number. The thermodynamics model made use of the NASA Lewis curve-fit ${ }^{\mathbf{1 4 , 1 5}}$ forms for thermally perfect gases, with local extensions of the valid ranges derived from J ANAF ${ }^{\mathbf{1 6}}$ and National Bureau of Standards ${ }^{\mathbf{1 7}}$ data. Such extensions were necessary to model the low free stream static temperatures representative of the Langley 31-Inch Mach 10 Tunnel. The transport properties were based upon Sutherland's model, using Wilke's rule for mixtures.

Wall temperatures on all model surfaces were held constant, as if the model was being actively cooled. F or the majority of cases the wall temperature $\mathrm{T}_{\mathrm{w}}$ was chosen as $90^{\circ} \mathrm{F}$, but the GASP code exhibited numerical instability for the two cases employing the hot six species exhaust gas model. For these cases the wall temperature was increased to $260^{\circ} \mathrm{F}$, the minimum to achieve numerical stability. The effect of this change in $T_{\mathrm{w}}$ remains to be determined.

Separate structured grids were generated for the TTD forebody, each internal nozzle, and the aftbody. Only half of the full configuration was modeled based upon symmetry about a vertical center-plane. The forebody grid dimensions were 45 cells streamwise, 64 cells normal to the body, and 64 cells wrapping around the body from upper symmetry plane to lower symmetry plane. The internal nozzle grids all consisted of 44 cells streamwise, 80 cells vertically, and 68 cells spanwise from the center splitter plate to thesidewall. The aftbody grid dimensions were 70 cells streamwise, 64 cells normal to the body, and 128 cells wrapping from upper to lower symmetry plane. Thus, the grid sizes for the half-span numerical models were forebody: 184,320 cells, nozzles: 239,360 cells, and aftbody: 573,440 cells, for a sum total of 997,120 computational cells. The forebody calculation took about $775 \mathrm{cpu}$ seconds on a CRAY C-90. Typical internal nozzle solutions required $300 \mathrm{C}-90 \mathrm{cpu}$ seconds for cold air and 2600 seconds for a hot six-species exhaust. Typical aftbody calculations required 1100 C-90 cpu seconds for cold air exhaust, 3700 seconds for hot two-species exhaust, and 21,550 seconds for hot six-species exhaust.

The grids were clustered near the body for accurate resolution of boundary layers. The inner law variable, $\mathrm{y}^{+}=\sqrt{\rho_{1} \mathrm{u}_{1} \Delta \mathrm{Y}_{1} / \mu_{1}}$, provides a measure of accuracy of the viscous solutions by combining density $\rho$, velocity $u$, and viscosity $\mu$ with the amount of point spacing normal to the surface $\Delta \mathrm{Y}$, all computed at the first computational cell center off the body (denoted by the subscript 1). Typically, $y^{+}$values of the order of 1 will ensure reasonable grid-point resolution of turbulent shear layers and, thus, excellent resolution of laminar boundary layers. In the forebody calculation the cell $\mathrm{y}^{+}$values averaged 0.76 , with a local maximum of 4.3 , occurring along the outboard edge of the inlet fairing. On most of the fairing surface the $\mathrm{y}^{+}$values averaged about 2 . In the aftbody calculations the average $\mathrm{y}^{+}$values were between 2 and 2.5, with local peaks of 6.7 at the lower wing/body juncture and a spike of 24 along the wing leading edge (near the stagnation line).

External body forces and moments were calculated by integration of computed surface pressure and skin friction data. Bilinear distributions of these quantities were assumed over each quadrilateral surface grid cell. Normal force components were computed by integration 
of the pressure over projected areas normal to each of the three cartesian directions. Tangential force components were computed from surface skin friction coefficients using velocity components at the first cell center off the body surface to resolve directions. The normal and tangential force components were summed over all surface grid cells to obtain total force components. Cell pitching moments were computed assuming that the cell forces acted at the cell centroid. Summation of the cell pitching moment values yielded total body pitching moments.

\section{Results}

Data comparisons presented below consist of two basic types: external forces and moments on the aftbody, and contours of plume parameters, in order to illustrate both surface and flow field effects.

\section{Forces and Moments}

Figure 6 shows longitudinal aftbody force and moment components normalized by the magnitudes of the forces and moments of the hot scramjet combustion products simulation, using the (more complete) six-species combustion products mixture at the baseline NPR $=3000$, plotted versus $\mathrm{SNPR}_{4}$. Each of the simulant exhaust approximations described in Table 1 are shown, including the single data point for hot air exhaust. In general, for a given exhaust mixture at a given total temperature the variations with respect to $\mathrm{SNPR}_{4}$ are nearly linear. Note the large SNPR 4 value (50.8) for the cold air exhaust at the baseline NPR $=3000$ compared to the other gases (see Figure 5). The NPR $=2050$ cold air case was run to allow comparisons at the $\mathrm{SNPR}_{4}$ of the baseline case $\left(\mathrm{SNPR}_{4}=35.5\right)$ without extrapolation.

The aftbody lift shows the least sensitivity to exhaust mixture or temperature. The slopes of the curves all agree to within $2 \%$. The two-species approximation of combustion products agrees well with the six-species model. The cold air results show excellent agreement at corresponding values of $\mathrm{SNPR}_{4}$, while the cold $\mathrm{CF}_{4}$-Ar results are $4.8 \%$ low. The pressure forces account for greater than $99 \%$ of the total aftbody lift regardless of exhaust gas; i.e., the contribution of skin friction to the lift is negligible.

Aftbody thrust is noticeably more sensitive to gas composition and temperature. Similar tolift, the slopes of thrust with respect to $\mathrm{SNPR}_{4}$ agree
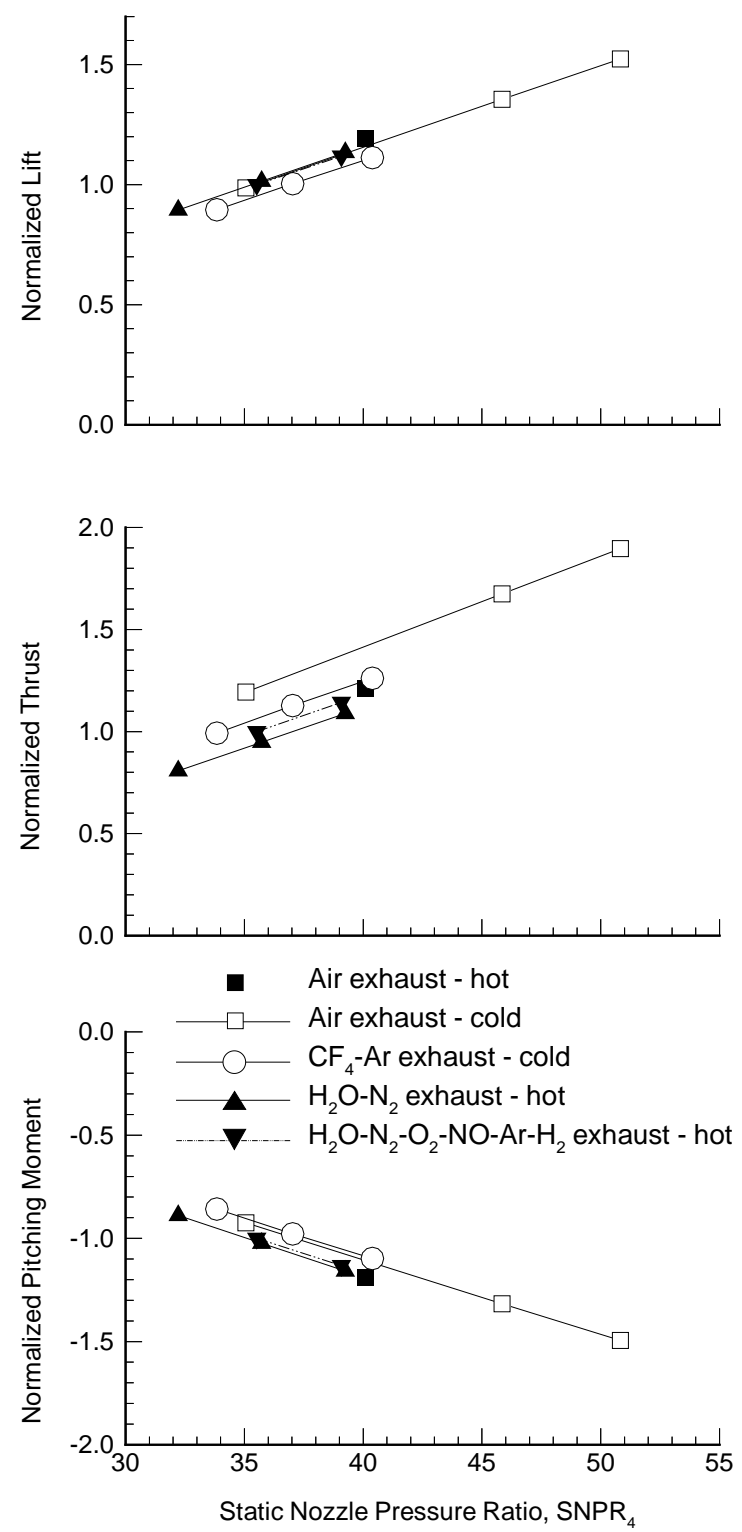

Figure 6. TTD aftbody force and moment comparisons

to within $2 \%$ except for cold air, which is approximately $10 \%$ greater than that of the six-species combustion model. The cold air thrust data over predicts the six-species combustion products thrust by about $21 \%$ at the baseline SNPR 4 . The cold $\mathrm{CF}_{4}$-Ar thrust data are about $6 \%$ higher, and the two-species combustion model $6 \%$ lower, than the six-species combustion model. The skin friction contribution (actually, drag) amounts to a significant percentage of total aftbody thrust. Specifically, the viscous drag is about $27 \%$ of the magnitude of the pressure contribution for the hot six-species exhaust, and about $20 \%$ for the cold $\mathrm{CF}_{4}$-Ar exhaust. This decrease in viscous 
drag, relative to the pressure thrust, for the cold exhausts contributes to the corresponding higher aftbody thrusts.

The trends in pitching moment are combinations of the trends in lift and thrust since the moment calculations are functions of both force components. The combustion models agree in magnitude within about $1.5 \%$, and the cold $\mathrm{CF}_{4-}$ $\mathrm{Ar}$ and air results are $8 \%$ and $6 \%$ high, respectively. The slopes of pitching moment versus $\mathrm{SNPR}_{4}$ all agree within about $4 \%$. Similar to lift, the pressure contribution is about $99 \%$ of the aftbody pitching moment.

The single hot-air data point on each plot of Figure 6 illustrates the temperature effects on a specific gas. The combustion products mixtures and the cold $\mathrm{CF}_{4}$-Ar mixture have ratios of specific heats in the range of 1.25 to 1.28 at the nozzle exit. At nozzle exit temperatures of $3400^{\circ} \mathrm{R}$ the ratio of specific heats for air is reduced from 1.4 at 'cold' temperatures to approximately 1.3. However, within the internal nozzle the hot-air temperatures are even higher, dissociation would be expected, and the thermally perfect assumption for air made in this ideal computational study is no longer valid. Thus, heating air exhaust to high temperatures to reduce the ratio of specific heats is not practical, even though the ideal thermally perfect data shown herein would indicate that results from such a technique would be better than using cold air.

\section{Plume Flow Field}

Figure 7 illustrates the resultant exhaust plume shapes and extents for two of the solutions at similar values of $\mathrm{SNPR}_{4}$. J et exhaust mass fraction contours are plotted on a plane normal to the free stream at the body trailing edge. The right half of the plot is the hot six-species exhaust model of the scramjet combustion products. The left side shows similar contours for a cold-gas simulation using the $\mathrm{CF}_{4}$-Ar exhaust mixture. The cases are characterized by the exhaust gas mixture and by the value of $\mathrm{T}_{4}$, an average temperature across the nozzle exit plane (station 4).

In general, the plumes are similar in both size and shape. The cold $\mathrm{CF}_{4}$-Ar plume is slightly larger both vertically and laterally, but at a slightly higher value of $\mathrm{SNPR}_{4}$ (about 3.3\%). Thus, some of the plume size difference is probably due to the increase in $\mathrm{SNPR}_{4}$. Figure 6 shows a corresponding $5.7 \%$ increase in thrust for the cold $\mathrm{CF}_{4}$-Ar exhaust. However, the same figure shows a $4.3 \%$ decrease in lift for the cold $\mathrm{CF}_{4}-\mathrm{Ar}$

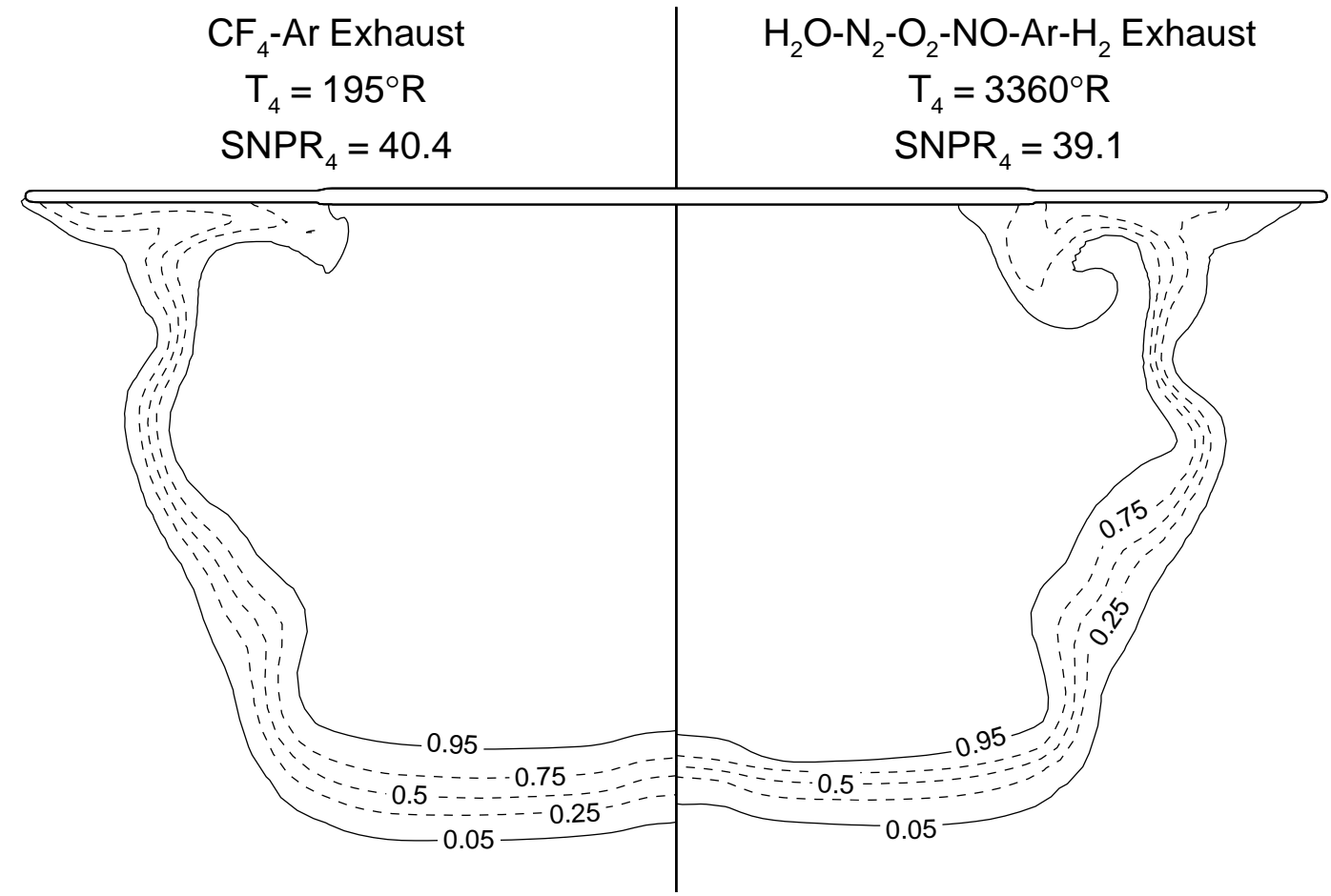

Figure 7. Plume exhaust mass fractions at the TTD body trailing edge 
exhaust, indicating that pressure gradients within the plume are affected by the exhaust mixture. Figure 8 supports these trends and illustrates this change in pressure gradients by comparing pressure ratio contours $\left(\mathrm{p} / \mathrm{p}_{\infty}\right)$ on the lower surface of the aftbody for the cold $\mathrm{CF}_{4}-\mathrm{Ar}$ and the hot six-species exhausts. N ote along the centerline the reversal in the mismatch of contours 2 and 10. Figure 8 also shows that, for either exhaust gas, the entire lower aftbody surface has a positive net force (i.e., no overexpansion). A similar analysis of the skin friction (not presented) shows that viscous drag of the cold exhausts is about half that of the hot exhaust.

The simulant gas concept ${ }^{\mathbf{1}}$ is ideally based upon matching Mach number, static pressure ratio, and $\gamma$ throughout the exhaust flow field. These three parameters were closely achieved within this study, except for the $\gamma$ of the air exhaust. All of the internal nozzles were designed for an exit plane Mach number of approximately 3.4, and SNPR 4 values of approximately 35 were achieved for all exhaust gases. Figure 9 shows the variation of $\gamma$ along an arbitrary streamwise computational grid line within the plume for five calculations plotted versus a normalized aftbody length (cowl trailing edge to body trailing edge). As previously noted, the $\gamma$ of cold air is a poor match for that of the combustion products. The hot air $\gamma$ is somewhat better, but still high. The cold $\mathrm{CF}_{4}$-Ar agrees much better at the nozzle exit, but the gradients of $\gamma$ versus length are too large just downstream of the cowl trailing edge. This variation is similar to the surface pressure gradient variation seen in Figure 8.

Thus, the high pressure exhaust flow at the nozzle exit expands more rapidly in the $\mathrm{CF}_{4}-\mathrm{Ar}$ plume than in the combustion products plume due to the thermodynamic properties of the gas. The overall plume size and shape is affected only slightly, as is the thrust which is dominated by the pressures near the nozzle. However, the aftbody lift force is distributed more evenly over the entire aftbody and is affected more by the streamwise pressure gradients.

\section{Conclusions}

A computational study has been performed to investigate the accuracy and validity of cold-gas simulation of actual hot scramjet exhausts

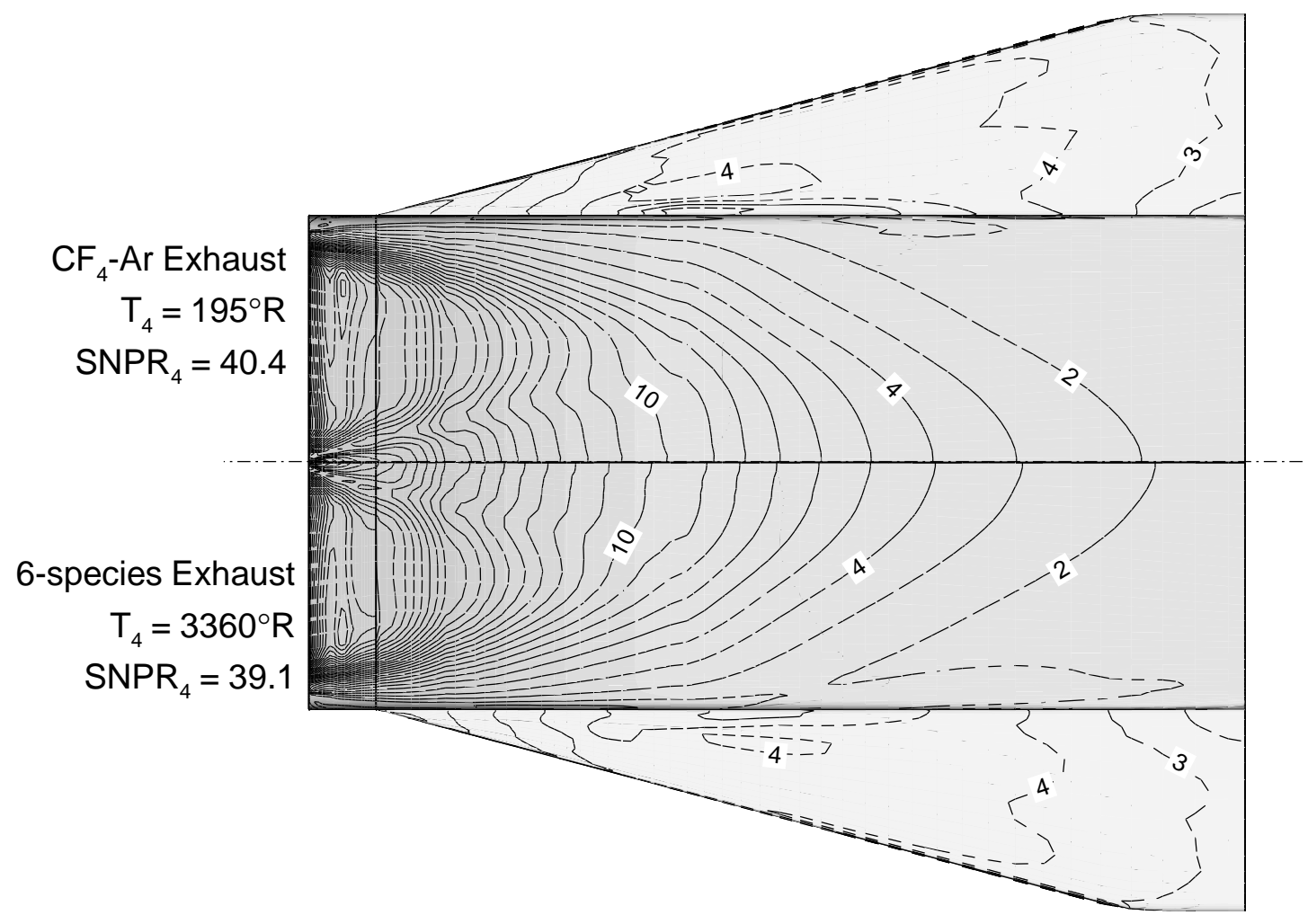

Figure 8. TTD aftbody lower surface pressure ratio contours, $p / p_{\infty}$ 


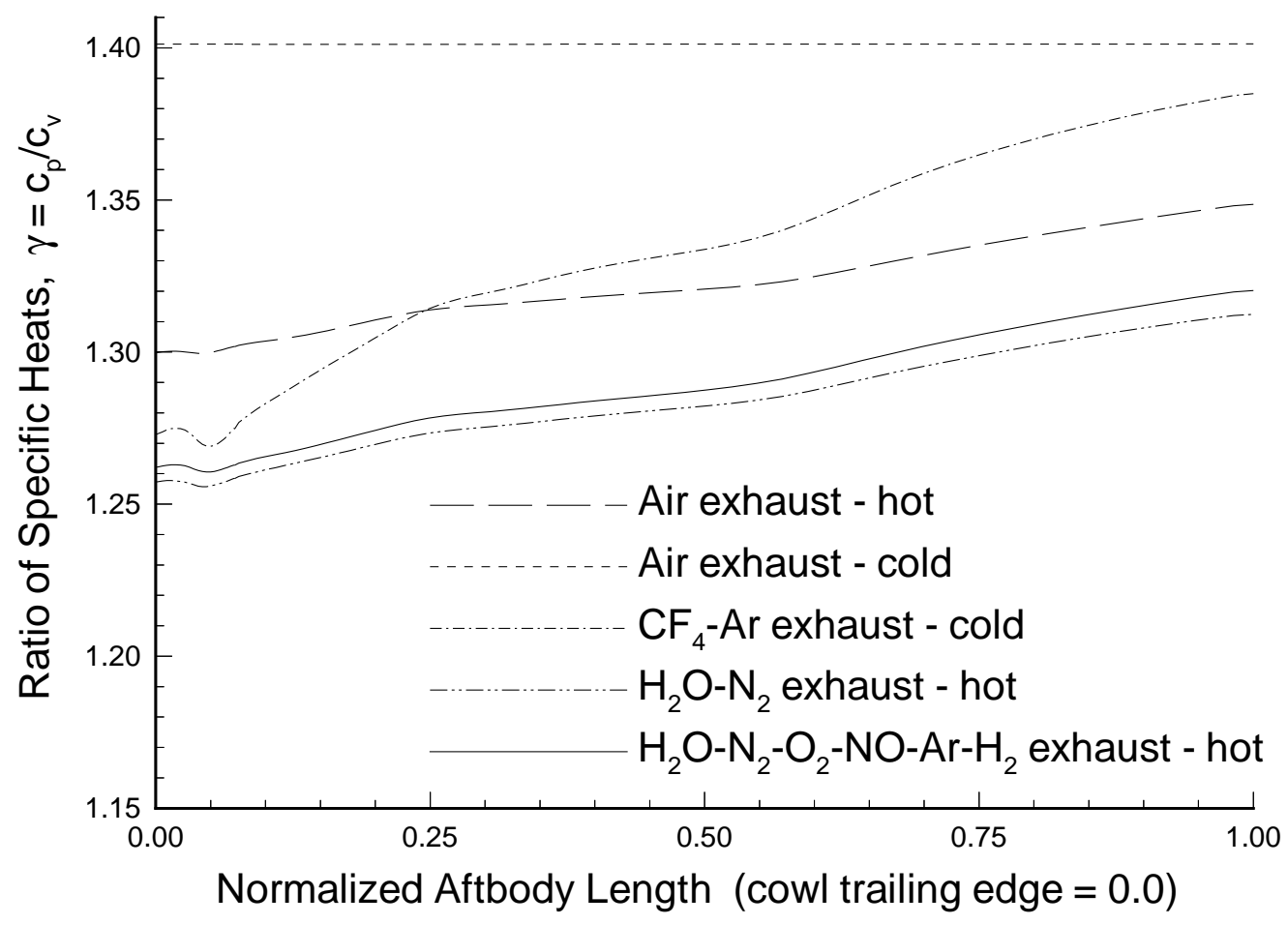

Figure 9. Comparison of exhaust gas ratios of specific heats within the exhaust plume

within a Mach 10 free stream over a representative single-stage-to-orbit airbreathing configuration. In particular, exhausts of various noncombusting chemistry models were studied to characterize their effects on the vehicle aftbody performance and plume flow field definition. Two approximations of the scramjet combustion products were utilized to determine the requirement for expensive, multi-species numerical modeling, and to establish a baseline for the validation of cold-gas simulation.

Based solely upon economy, cold (ambient) air is the optimum simulant exhaust gas. It is readily available at high pressure and poses little or no environmental or biological hazards. However, from a technical viewpoint, cold air was shown to provide poor simulation of the aftbody thrust. Hot air appears to show improved thrust results relative to the combustion products, but the exhaust temperatures required are higher than those at which air begins to dissociate. Wind tunnel testing at such temperatures would be difficult and the air exhaust would not be thermally perfect.
A cold $\mathrm{CF}_{4}$-Ar mixture provides a much better representation of the hot combustion products exhaust. The ratio of specific heats at the nozzle exit more closely matches that of hot scramjet exhaust than does the $\gamma$ of cold or hot air. Thelift, thrust, and pitching moment components are all simulated within approximately 5-6\% accuracy by the cold $\mathrm{CF}_{4}$-Ar exhaust while the air exhaust accuracy is inconsistent: good for lift, poor for thrust, and moderate for pitching moment.

The plume definition of the cold $\mathrm{CF}_{4}-\mathrm{Ar}$ exhaust agrees well with the combustion products exhaust. Differences of pressure gradients within the plume are shown to be functions of thermodynamic properties of the two mixtures. However, these gradient differences are of much less importance in scramjet exhaust simulation than the basic premises of matching static conditions at the nozzle exit, particularly $\gamma$. It is possible that a better simulant exhaust gas than a 70/ $30 \%$ mole fraction mixture of $\mathrm{CF}_{4}$ and argon can be identified to improve the simulation of actual scramjet combustion products with regard to $\gamma$. These results show that cold-gas simulation at Mach 10 is a viable technique for reproducing 
hot scramjet exhaust effects when an appropriate thermally perfect gas mixture is used.

Finally, the use of two different hot approximations of the scramjet combustion products in the numerical solutions showed that the less abundant components ( $4 \%$ and less, each, by mole fraction) do affect the exhaust characteristics slightly. However, only the thrust shows a discrepancy of more than $2 \%$. Thus, the two-species approximation is acceptable if the computational cost is significant, but for accurate thrust calculations the six-species model should be employed.

\section{References}

1. Oman, R. A.; Foreman, K. M.; Leng, J .; and Hopkins, H. B.: Simulation of Hypersonic Scramjet Exhaust. NASA CR-2494, March 1975.

2. Hopkins, H. B.; Konopka, W.; and Leng, J .: Validation of Scramjet Exhaust Simulation Technique NASA CR-2688, J une 1976.

3. Cubbage, J ames M.; and Monta, William J .: Parametric Experimental Investigation of a Scramjet Nozzle at Mach 6 With Freon and Argon or Air Used for Exhaust Simulation. NASA TP 3048, February 1991.

4. Tatum, Kenneth E.; and Huebner, Lawrence D.: A Preliminary CFD Study of Angle-ofAttack Effects on a Powered Hypersonic Model. NASP CR 1154, April 1993.

5. Huebner, Lawrence D.; and Tatum, Kenneth E.: CFD Code Calibration and Inlet-Fairing Effects on a 3D Hypersonic Powered-Simulation Model. AIAA-93-3041, AIAA 24th Fluid Dynamics Conference, J uly 6-9, 1993.

6. Tatum, Kenneth E.; Huebner, Lawrence D.; and Witte, David W.: Computati onal Study on the Use of Simulant Gas in Powered, Hypersonic Air-Breathing Models. NASP TP 1007, October 1992.

7. Tatum, Kenneth E.; and Huebner, Lawrence D.: A 3D CFD Study on Simulated Exhaust Plumes. Paper No. 38, 1993 National AeroSpace Plane Technology Review, Monterey, CA, April 13-16, 1993.

8. Witte, David W.; Huebner, Lawrence D.; and Haynes, Davy A.: Test Technique for Using Metric Model Parts To Obtain Powered Effects on Air-Breathing Configurations in Hypersonic Facilities. NASP TP 1008, October 1993.

9. Everhart, J oel L.; Ashby, George C., J r.; and Monta, William J .: Test Description and Preliminary Pitot-Pressure Surveys for Langley Test Technique Demonstrator at Mach 6. AIAA-92-3940, AIAA 17th Aerospace Ground Testing Conference, J uly 6-8, 1992.

10. Huebner, Lawrence D.; and Tatum, Kenneth E.: Computational Effects of Inlet Representation on Powered Hypersonic, Airbreathing Models. AI AA J ournal of Aircraft, Vol. 30, No. 5, September-October 1993, pp. 571-577.

11. McGrory, William F.; Huebner, Lawrence D.; Slack, David C.; and Walters, Robert W.: Development and Application of GASP 2.0. AIAA-92-5067, December 1992.

12. Huebner, Lawrence D.; and Haynes, Davy A.: Forebody Redesign and Flow Characterization of Test Technique Demonstrator at Mach 6. NASP TP 1013, April 1994.

13. Huebner, Lawrence D.; and Tatum, Kenneth E.: Computational and Experimental Aftbody Flow Fields for Hypersonic, Airbreathing Configurations with Scramjet Exhaust Flow Simulation. AIAA-91-1709, AIAA 22nd Fluid Dynamics, Plasma Dynamics \& Lasers Conference, J une 24-26, 1991.

14. McBride, Bonnie J ; Heimel, Sheldon; Ehlers, J anet D.; and Gordon, Sanford: Thermodynamic Properties to $6000^{\circ} \mathrm{K}$ for 210 Substances Involving the First 18 Elements. NASA SP-3001, 1963.

15. Rate Constant Committee, NASP HighSpeed Propulsion Technology Team: Hypersonic Combustion Kinetics. NASP TM-1107, NASP J PO, Wright-Patterson AFB, 1990.

16. J ANAF Thermochemical Tables, Second ed. NSRDS-NBS 37, U. S. Dep. Commerce, J une 1971.

17. Hilsenrath, J oseph; Beckett, Charles W.; Benedict, William S.; Fano, Lilla; Hoge, Harold J .; Masi, J oseph F.; Nuttall, Ralph L.; Touloukian, Yeram S.; and Woolley, Harold W.: Tables of Thermal Properties of Gases. NBS Circ. 564, U. S. Dep. Commerce, Nov. 1, 1955. 